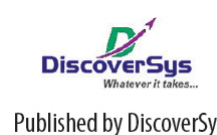

Published by DiscoverSys

\section{The ways urban marginalized group conceptualizes health and wellbeing: The case of the waste pickers in Surabaya, Indonesia}

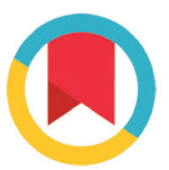

CrossMark

\author{
Yohanes Kambaru Windi, ${ }^{1 *}$ Dyah Wijayanti, ${ }^{1}$ Eko Rustamaji Wiyatno ${ }^{1}$
}

\begin{abstract}
Background and purpose: Health and wellbeing have a different meaning for an individual, institution, ethnicity and organization. The study aims to overview the ways waste pickers conceptualize health and wellbeing.

Methods: A qualitative procedure deployed to identify the predictors of health and wellbeing according to the waste pickers and how they perceive them. Forty waste pickers were involved as participants. Semi-structured in-depth interviews, natural group discussion (NGD) and casual conversation are the main methods for collecting information. The information was analysed using a thematic and inductive approach.
\end{abstract}

Results: The waste pickers identify health as free from diseases and illness, being able to work, a peaceful mind, positive relation within the family and social life, being grateful for life, surrender to God, and being happy. They relate wellbeing with gratefulness with achievements, sense of enough, being satisfied with life, submission to God, sense of "enough", frugality and some assets back hometown.

Conclusion: The study concludes that waste pickers provide a practical understanding of health and wellbeing. It recommends that understanding and measuring health and wellbeing should on the context of the target population.

Keywords: waste pickers, health, wellbeing, perception

Cite this Article: Windi. Y.K., Wijayanti, D., Wiyatno, E.R. 2020. The ways urban marginalized group conceptualizes health and wellbeing: The case of the waste pickers in Surabaya, Indonesia. Public Health and Preventive Medicine Archive 8(2): 106-112. D0I: 10.15562/phpma. v8i2.304

${ }^{1}$ Poltekkes Kemenkes Surabaya, Indonesia

*Correspondence to: Yohanes Kambaru Windi; Poltekkes Kemenkes Surabaya, Indonesia; windi.yohanes@poltekkesd epkes-sby.ac.id

\section{INTRODUCTION}

Health means a different thing for individual, institution, ethnicity and culture groups. The overarching concept of health draws extensive discussion and debates among scholars. Starting from the era of traditional medicine, the definition of WHO (1948), the Ottawa Charter (1986) up to date, health concept is a vocal point of debate, critiques and needing redefinition. ${ }^{1-3}$ Consequently, various health definitions emerged to fulfill the context and fill up the gaps in the field of studies.

Scholars argue that health and wellbeing interlink each other. ${ }^{6-8}$ A healthy person is assumed to have positive wellbeing and vice versa. Wellbeing evolutes since the time of Aristotle, recently diverse into different disciplines, and becomes a popular topic in the contemporary works of literature. ${ }^{6,7}$ The concept has been expanding to become a multidisciplinary and multi-interpretative concept ranging from psychology, economics, anthropology, social and religion. Wellbeing generally relates to or frequently interchanges with the quality of life, happiness, life satisfaction, welfare, well living, living standard, utility, prosperity and needs fulfillment. Others assume wellbeing as development, empowerment, capability expansion, human development, poverty, etc. of an individual, group of people or a nation. ${ }^{8-10}$
Since health and wellbeing are multi-interpreted, it is interesting to explore how poor and marginalized groups conceptualize the concepts. The study uses waste picker as the case. Waste picker is an urban poor group relying on collecting, sorting and selling recyclable waste for a living. ${ }^{11,12}$ The waste picker is an urban poor group, vulnerable and marginalized group having limited access to social benefits, including freshwater, housing, electricity and health services. They also stigmatized as criminal, with homelessness, unemployment, poverty and backwardness. ${ }^{13}$ The study assumes that these conditions may influence the ways waste pickers perceive health and wellbeing. Our knowledge of the ways the waste pickers conceptualize health and wellbeing is lacking. The study, therefore, aims to overview the ways waste pickers conceptualize health and wellbeing.

\section{METHODS}

A qualitative approach overviews the ways waste pickers conceptualize health and wellbeing. The study takes place at Benowo Landfill and Krembangan Selatan temporary waste dumpsite, Surabaya. Forty waste pickers were recruited as informants using a snowballing system. Twenty waste pickers were interviewed, 10 waste pickers 
participated in two natural group discussion/ NGDs (5 for each), and 10 others involved in casual conversation. The theoretical foundation of the study is that health and wellbeing are dynamic concepts and defined differently by individual, groups, ethnicity, or institution. The study explores the two variables: health and wellbeing from the perspective of poor group, represented by waste pickers in Surabaya. Plain language statement of the research and consent form available for each interviewee. All means of information collection were audio-taped, and consents were required. Information was transcribed, analyzed using the thematic procedure, and inductively to draw some emerging concepts of health and wellbeing.

Ethical clearance was granted by Monash University Human Research Ethics Committee (MUHREC) Project Number: CF14/23642014001267. The Board of National Unity, Politic, and Community Protection of East Java Province granted the research permission on 6 January 2016, Number 070/139/203.3/2016, and Surabaya Municipal also granted research permission on 14 January 2016, Number 070/0545/436.7.3/2016.

\section{RESULTS}

\section{Concept of Health}

The data analysis generates some information regarding the concept of health of the waste pickers in Surabaya. The main themes of health, including the absence of diseases and illness, being able to work, a peaceful mind, surrender to God, positive relationships within the family and social life, being grateful for life, and being happy.

\section{Free from Disease or IIIness}

Health always relates to disease and illness. Most waste pickers claim that being healthy, anyone should free from any disease, illness, and other physical and psychological impairments. Some others relate health with the environment, free from problems, and healthy foods. Following are remarks of the waste pickers about the concept of health:

Healthy people have no disease or illness, a peaceful heart, and do not many things bother our minds. We should have no stress on our life, do not have a bad relationship with family (Mr. $Z L, 26$ years old)

Being healthy means we don't get sick or illness, our physic is also in good shape and our mind (Java Language: segar waras). Do not overload our minds with many things. Make life easy and stay away from problems (Mrs. CHTJH, 36 years old)

To get healthy if your environment is clean and healthy. You need to take care of your house and surroundings. Even though we live in this slum area, we should ensure that our compound is clean and save (Mrs. MWJ, 28 years old)

Being healthy depends on us. We need to care what we eat, not much meat that triggers cholesterol, hypertension, uric acid. We need to eat veggies, fruits, and less sugar. Health means those things. Drink much water, not alcohol "haram" (forbidden) (Miss EST, 34 years old)

\section{Being able to work}

Being healthy constitutes with the ability to perform daily work. Some waste pickers perceive "being able to work" as an indicator of health. Mrs. Maki (30 years old), stated health as:

"If you can work means you are healthy. People like us have a choice. Need to work. You only work if you're healthy. Healthy people can work. If you sick, you can't work. We need to work for a living and getting healthy."

\section{Peaceful Mind}

A peaceful mind is an essential indicator of health. The waste pickers believe that having a peaceful mind indicates a healthy person. A healthy mind emerges from persisting self-awareness of being poor, and acceptance of that condition. They argue that a healthy individual depends on the state of mind of the individual. Mr. Khol (41 years old) acknowledged:

We are poor people. We must try to live in that situation. Importantly, you are healthy when you don't have anything bother your thought-not overthinking. Just accept what you have now. If you have many burdens on your mind, you may get sick. Getting health means getting no burden on your mind."

\section{Positive Social Relation}

Social relationship plays a vital role in the health of an individual. Positive relationships within the family and social environment are predictors of health. Good health is inseparable from improving rewarding relationships with other people. Once, Mrs. MKY (37 years old) argued that:

Healthy people are those who have no problem with their families. No arguing between husband and wife or children. If someone does not behave well to others, it would be unhealthy. Not healthy at all. Similarly, we should have a good relationship with our neighbours. Do not get jealous if they have this or that. No gossiping.

\section{Being Grateful}

Some reviews reveal that health is associated with the sense of thankfulness of their achievement. 
They believe that becomes a waste picker is not the primary choice when they move to Surabaya. However, they argue that being a waste picker is a blessing as they may earn money to support their family back hometown. They believe it is a "rejeki" or blessing from Almighty God, and they oblige to be grateful. The feelings make them keep healthy. Health is a way to recognize God's grace. Mrs. Muh (70 years old) described that:

I am grateful for all I have at the moment. Thank God, I am an old woman, but earning money from waste picking is a blessing for me. That makes me feel good and healthy. No disease. I am fine. I always thankful. By feeling that way, I think my body is healthy. Always be grateful for God's gives. If not, you'll be sick.

\section{Happiness}

Health may associate with the psychological traits of an individual. Happiness is a notion of the health condition of an individual. Aslan (male, 73 years old) describes happiness indicates good health. He said:

Health person needs to have a peaceful mind, always happy, full of smile in facing this life. I remember the doctor said to me to be happy in my life. Even though we are poor, have no money, just try to be happy. You will be healthy. If you take all matters as a problem, you will not be happy, and you'll get sick. So just relax, don't think much, follow life goes, and always happy. That's what I experienced. Being 73 years old is not easy for me. But happiness makes me feel healthier.

\section{Life Satisfaction}

Waste pickers with all their shortcomings; life satisfaction is something challenging to achieve. For commoners, the realities that waste pickers live in a crowded-slum area with limited public benefits and working in an unhealthy and unsafe environment, satisfaction seems to be a luxury thing. The study, however, reveals different facts. Regardless of the unfortunate life, waste pickers believe that life satisfaction determines their health. Life satisfaction promotes positive intrinsic drivers to feel healthy. Mr. KHL, (26 years old) stated that:

I think, healthiness always depends on how we rate our condition. We are poor, earning is not stable, sometimes we get much another time we get nothing. We don't have many options. What we need is just to try to satisfy all we get today. If you think the life-burdens too much, you get sick. Not healthy anymore. Satisfaction and gratefulness to God Almighty may release our life difficulties. And that makes you healthy. We stuck here with the waste. No way out. Satisfied and being acceptable (or "nrimo" in Java language) with our condition will save you from illness.

\section{Surrender to God "Tawaqal"}

The waste pickers classify being surrender to Allah's will is an essential element of health. Health, prosperity, bad luck are God's authority, and humankind are subjected to surrender. The waste pickers believe that waste picking is God's way to make them survive in the city. Mr. DDT (49 years old) claimed:

As a Moslem, I believe everything that happened to my life is because of Allah's will. Even though you are rich, if God says you sick, you will be sick. We work with garbage, smell bad, live around the landfill with cattle, rats everywhere. But we do not get sick. Look at those rich people, live in a clean and healthy house, good foods, they have everything, they may get a heart attack, hypertension, diabetes (rich people illness). We poor people here live with rubbish; we may only suffer from coughing, itching, cuts, fever, or flu. I believe that everything happens to us because of God's hand. Tawaqal or Ikhlas (being surrender to God) will make us safe and healthy.

\section{Concept of Wellbeing}

The waste pickers indicate some features of wellbeing. They identify wellbeing as a sense of gratefulness, easy-going lifestyle, life satisfaction, fulfilling daily needs, schooling for children, and some properties in their hometown. The following are the ways waste pickers describe wellbeing.

\section{Gratefulness}

Most of the waste pickers come from Madura (an island on the East tip of Java island), known for their determination for the Islamic faith. All live events frequently relate to their creator, Almighty God. They believe that what they have, experience, fortune, and unfortunate are beyond their control instead of God. Mr. SGYT (31 years old) claims that: Wellbeing relates our gratefulness being able to eat, pocket money for the children. We thankful to God if we could afford those things. Thank God if we can have more than that. Save a little money for this year Idhul Fitrie Feast.

Mr. ASL (73 years old), supports the above statement. He describes wellbeing as:

Even though the earning of waste picking not much, that is not a problem. We get more or less form this working; importantly, we need to be thankful to God for His blessing. If we got a lot of money, we might eat delicious food, but if not, salted fishes would be fine for me. That's my 
fortune of the day. Thank God.

\section{Satisfaction}

Even though waste picking is frequently associated with poverty, unhealthy, uneducated, waste pickers are still happy with their work. They satisfy with their achievement, including providing daily needs of their family, education for their children. Satisfaction is measured as an indicator of wellbeing. I think I love my life like now. Waste picking is not my purpose of coming here (Surabaya). I want to work in construction, but I ended as a waste picker. The first time is very frustrating, but by the time goes I began to love the job. The earning is not much, but I tried to save cents by cents for my children, food for my family at hometown. Now, I satisfy with all I have. That is why I see this work is good for my life dan family. Satisfaction to what I got, is a way for me to keep staying in this work (ET, 35 years old woman)

\section{Sense of Enough and Frugal Lifestyle}

Waste picking is an unpredictable work in terms of income. However, they feel satisfied with their earnings and attempt to adjust their earning with their spending. The term adjustment refers to the sense of enough, frugal lifestyle by selecting the most basic needs, especially daily foods. Mrs. KTJH, (47 years old), describes as following:

In my opinion, if you feel enough about what you get, that I call wellbeing. Be grateful for what we eat now, no matter what the food is. Sometimes we just eat rice and "sambal" (Chilly sauce). That is enough. Importantly we get full. At least we have something to protect us from the hot and rainy season. That is enough for wellbeing. We eat as simple as possible, and that is enough you do not get hungry. We are happy with what we have.

\section{Tawaqal (being surrender to God's will)}

When health relates to gratefulness to God's blessings, the waste pickers also describe the importance of "Tawaqal" or surrender to God's will as an indicator of wellbeing. The waste pickers measure wellbeing as the acceptance of God's will. By surrender, they avoid themselves from expecting life outcomes beyond their capability. The sense of submission will guide the waste pickers in setting up their wellbeing.

We are only human. We have no power to change our fate. That's all depends on God's wills. Our responsibility just to work hard, not lazy. We work hard to collect waste. It is our fortune that much waste gathers, but there is time we got not that much. We all only "tawaqal" leave everything for God's hand. By this feeling, we feel comfortable and feel okay with our life (RDN, 51 years old woman)

\section{Social Relation}

The waste pickers also rate their wellbeing from the positive social relation aspect. Building up social cohesion, especially with other waste pickers, improves the group members' sense of wellbeing. Avoiding conflict with other people, including family members, increase the understanding of wellbeing. Once, Mr. ZL, (46 years old), suggested:

I will feel okay if I have a good relationship with my neighbours. In a family as well, husband and wife, and children need to maintain their wellbeing by having good relationships. By doing so, I will feel comfortable, no "enemies," no rivals in life. People should feel that way to have positive wellbeing

\section{Properties or Assets}

The waste pickers identify wellbeing as the ownership of some "properties." But the term property is far from the most people imagined, such as apartments, shares, investments, luxurious housing or cars, or jewellery. The sense of properties among the waste pickers are simply related to having a liveable house, "good furniture," rice fields, number of cattle (i.e., buffalo, cows, goats), motorbikes or stereo system. Some waste pickers emphasized the issues as followings:

We may have good wellbeing if we have some belongings. We dream of having a good house back in my hometown with TV or radio cassettes. I do have two buffaloes in my village. My parents take care of them. I bought them when they were little, and now they are growing bigger and bigger. I want to sell them to purchase a motorbike. But I won't bring the motorcycle here. Just leave it in the village. I will use it when return home during the "lebaran" (annual Islamic holidays and fiesta) (GSR, 67 years old man)

\section{DISCUSSION}

The qualitative information above accentuates some ideas of health among the waste pickers in Surabaya. They conceptualize health as the absence of disease and illness, an investment to work, gratefulness, peaceful mind, happiness, positive social relation, life satisfaction, and surrender to God. The idea of health more practical, contextual, and slightly different from the existing definition. The WHO defines health as a state of complete physical, mental, and social wellbeing and not merely the absence of disease or infirmity. ${ }^{14}$ The most criticism against the WHO definition of health is the medicalization of society; the definition fails 
to accommodate the changes in population and the nature of diseases and illness, and impractical as it is hard to implement and evaluate. ${ }^{3}$

The absence of disease and infirmity is the critical element of the WHO definition of health. The concept is broad and hard to measure. The idea of health among waste pickers is simple, practical, and measurable. The waste pickers tend to view health positively and more operational. Peaceful mind, happiness, and life satisfaction perhaps the mental health's operationalization as noted by the WHO. Some studies reported that peaceful mind promotes health status both physic and psychic and reduce the symptoms of various illness such as dementia, anxiety, stress, and even cancer. ${ }^{15-17}$

The WHO definition of health "not merely the absence of disease...." implies that health concept is a dynamic subject to multi-interpretation and goes beyond the nature of health itself. The waste pickers describe the practical notion of health, which is "being able to work." Typically, a healthy person may optimize the working performance or productivity of an individual. The health condition of employees influences worker productivity. A healthy person who works more productive, as measured by The Centres of Diseases Control and Prevention, reminds employers that health conditions impact the working performance of their employees. ${ }^{18}$ The loss of productivity of the employee associate with bad health. ${ }^{19}$ Waste picking is a physically demanding job needing physical fitness. The job highly dependent on healthy and strong physical conditions of the waste pickers. Therefore, health means being able to perform their daily waste picking.

The waste pickers believe that happiness and life satisfaction contribute to good health. Sabatini found in Italy that happiness is a strong predictor

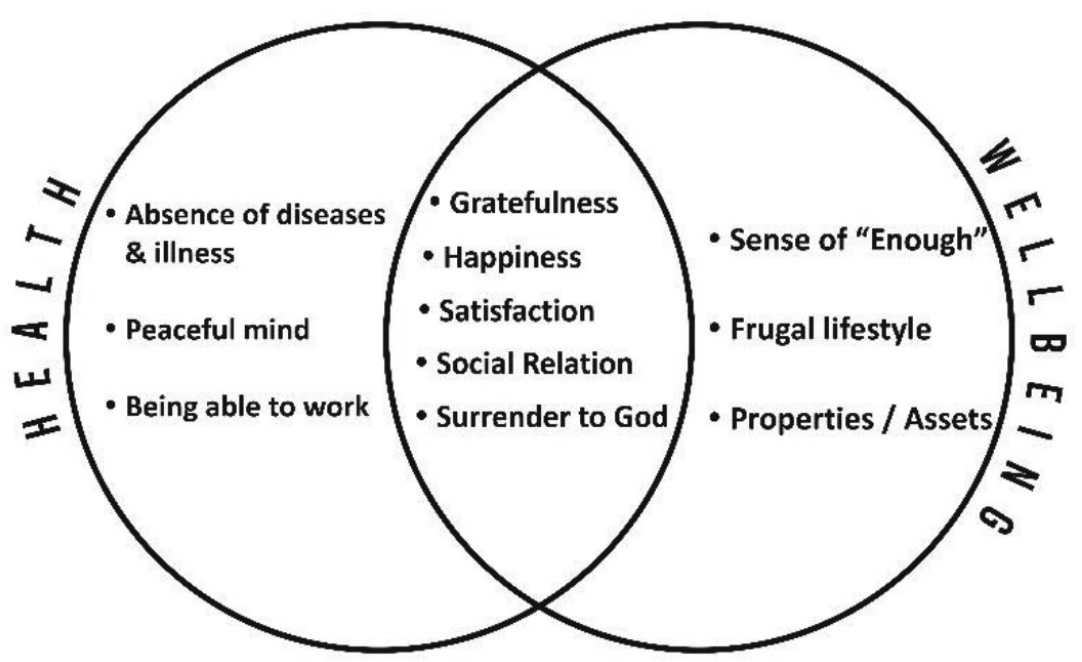

of health and prevents unwanted physiological reactions to life events. ${ }^{20} \mathrm{~A}$ multivariate model level study across 47 countries in Europe found the association between happiness and health. ${ }^{21}$ At one point, happiness does not cure illness, but it may prevent the individual from getting sick. ${ }^{20}$ Happiness and health interlink and mutually influence one another. A study describes that biological factors and health are the underlying factors of happiness. ${ }^{19}$ Happiness positively contributes to good health; on the other hand, health may produce happiness for individuals as they optimally enjoy their lives. Happiness is something that generates the satisfaction of an individual. Satisfaction brings a positive aura for the state of individual good health. According to Grant and colleagues, life satisfaction has a positive association with health behaviour practices, and they pose bidirectional influence. ${ }^{20}$

The WHO explains social wellbeing as an indicator of health. Social wellbeing refers to the quality of social interaction of individuals within a social engagement. The waste pickers assume that positive social relationship enhances their quality of life, especially on health. In contrast, social isolation harms the health status of people. Hawton and colleagues describe that social isolation is a burden for senior citizens' health and wellbeing. ${ }^{23}$ In medical therapy, we recognize the importance of biopsychosocial in healthcare. Social support becomes a model or determinant to improve the quality of healthcare together and a clinical intervention. $^{23-25}$

Religiosity becomes a critical element of the waste pickers' livelihood. Health is measured form the ways they conduct their lives in the guidance of faith values. Gratefulness and faithfulness are the predictors of health. Obeying and thankful for life influence their spiritual, psychological, and physical health. Some studies suggested that gratefulness and surrender to God link to stress reduction ${ }^{26} 099$ adults with type 2 diabetes mellitus from the Health and Retirement Study. Self-reported health status was examined at baseline and in 4 biennial survey waves (2003-2010; spirituality affects the self-management of diabetes. ${ }^{27}$ A study of religioushealth connection reveals that "giving up to God" is a useful model of health promotion intervention. ${ }^{28}$

In some points, waste pickers interconnect health and wellbeing. Health and wellbeing share similar predictors; gratefulness, happiness, satisfaction, surrender to God, and social relation. Figure 1 shows the intersection between health and wellbeing in the context of waste pickers in Surabaya.

Figure 1. The interconnection between health and wellbeing 
Wellbeing can be understood and widely used in the field of health, psychology, economics, welfare and prosperity, social life, or need fulfillment. The waste pickers identify wellbeing from the point of economy, psychology, needs fulfillment, social relation, and religious perspective. Gratitude reflects the spiritual wellbeing of the waste picker, believing that life is a gift from God; therefore, they are entitled to pay their thanks. Gratitude is a kind of thankfulness and appreciation that creates a positive feeling that influences individual wellbeing. ${ }^{29}$ The waste pickers feel secure on whatever blessing they receive, therefore, submitting (surrender) all their life to God. They believe that waste picking is a blessing from Almighty God, and they oblige to be grateful. For the waste pickers, the sense of gratefulness and being accepted for God's will is a coping mechanism to encounter life burdens.

A study in Phnom Penh, Vietnam revealed that the young waste pickers aware of their reality, unable to change the reality, but they can make a difference in the way they understand reality. ${ }^{30}$ The study also found that the waste pickers in Phnom Penh believe that their wellbeing is constructed by personal, interpersonal, and financial. Personally, the indicators of wellbeing range from physical health, good life, positive life perception, and independence. To assist friends in need, living in loving and caring family and friends, having genuine people around, and being a part of community activities are the ways the waste pickers express their interpersonal or social connection. Moreover, the study highlights the fulfillment of basic needs, and financial stability is determinants of wellbeing.

Awareness against the facts of their life, the waste pickers become adaptive and adjusted by practicing a frugal lifestyle and having the sense of "enough" for their achievement. Realizing the reality of limited earning, frugal lifestyle, and feeling "enough" are the coping mechanism to the condition. In this point, the aim of life and the expectation the live to be are ways to adjust with circumstances as waste pickers who working hard to survive. Furthermore, in religious practice, frugality refers to a simple lifestyle by minimum material consumption focusing on spiritual goods such as inner freedom, justice, social peace, or the quest of ultimate reality. ${ }^{31}$ The frugality of the waste pickers generally is a "spend-saving" practice and self-restriction on expensive goods during their time waste picking in Surabaya. For example, the waste pickers eat simple-plain foods and tend to live or hire a small room in a slum area or build their huts around the landfill. The frugality is practiced on purpose to save money back to hometown, schooling for children, build houses with fine furniture, or investing in land or cattle. The waste pickers identify wellbeing as the power of spiritual belief (gratefulness, submission to God), personal perception (happiness, satisfaction), rewarding social connection, frugality, sense of enough, and having assets.

When most of the definition of health and wellbeing proposed by formal organization (i.e. WHO) are massively quoted, the concept of health according to individu, group of ethnicity or culture group are frequently poorly concerned. Sunarno found that only $20 \%$ of the Java ethnic in Blitar match the definition of health according to WHO and Health Ministry of Indonesia and $80 \%$ uses the concept of health concept based on their experiences heavily influenced by Javanese culture. ${ }^{21}$ According to the study, the concept health is waras bandane (physical health), waras rohanine (psychological health), waras spiritual (spiritual health), waras sosiale (social health), kecukupan kebutuhane (fulfilment of needs), padang pikirane (healthy minds). The ethnic of Java and Bali conceptualize health as being able to work, being able to do daily acitivities, productivity and creativity, and achievement of spiritual aspect. ${ }^{22}$ This study re-emphasizes that the concept of health is dynamic and rich of meanings.

\section{CONCLUSION}

The study re-emphasizes that health and wellbeing is a different thing for individuals, groups, cultures, professions, ethnicities, or organization. However, health and wellbeing are inclusive, where intersection among fields is apparent and fill the gaps that other definition cast aside. The waste pickers in Surabaya define health as the absence of disease and illness, an investment to work, gratefulness, peaceful mind, happiness, positive social relation, life satisfaction, and surrender to God. They also believe that wellbeing is the combination of gratefulness, satisfaction, sense of enough by practicing a frugal lifestyle, being surrender to God, rewarding social relation, and having some "properties." Health and wellbeing interlink, interchange, and share some variables, including gratefulness, happiness, submission to God, satisfaction, and social relation. The implication of this study that decision-policy makers need to understand the concept of health and wellbeing of a certain group of people in formulating policies and health programs.

\section{REFERENCES}

1. Crinson I, Martino L. Public Health Textbook [Internet]. Health Knowledge. 2017 [cited 2020 Jun 18]. Available from: Health concept is a debatable and unfinished definition 
2. Bircher J. Scientific Contribution Towards a dynamic definition of health and disease. Med Heal Care Philos. 2005;8:335-341.

3. Huber M, Green L, Horst $\mathrm{H}$ van der, Jadad AR. How should we define health?. The BMJ. 2011;343.

4. Tov W. Well-Being Concepts and Components. Handb well-being. 2018;1-15.

5. Boehm JK, Kubzansky LD, Laura D. The heart's content: The association between positive psychological well-being and cardiovascular health. Psychol Bull. 2012;138(4):655691.

6. Diener E, Chan MY. Happy People Live Longer: Subjective Well-Being Contributes to Health and Longevity. Appl Psychol Heal Well-Being. 2011;3(1):1-43.

7. Krauts R, Zalta EN. Aristotle's Ethics [Internet]. Standford University Encyclopedia. 2018 [cited 2020 Jun 10]. Available from: https://plato.stanford.edu/entries/aristotleethics/

8. Gillett-swan JK, Sargeant J. Wellbeing as a Process of Accrual: Beyond Subjectivity and Beyond the Moment Citizenship, Well-Being and Sustainability: Epicurus or Aristotle ?】. Soc Indic Res. 2014;121(1);135-148.

9. Medina M. The informal recycling sector in developing countries Organizing waste pickers to enhance their impacts. Gridlines. 2008;44.

10. WIEGO. Waste Pickers [Internet]. WIEGO. 2013 [cited 2019 Jun 10]. Available from: https://www.wiego.org/ informal-economy/occupational-groups/waste-pickers

11. Paul JG, Arce-Jaque J, Ravena N, Villamor SP. Integration of the informal sector into municipal solid waste management in the Philippines - What does it need?. Waste Manag. 2012;32(11):2018-2028

12. World Health Organization. What is the WHO definition of health? [Internet]. World Health Organization. 2020 [cited 2020 Jul 10]. Available from: https://www.who.int/ about/who-we-are/frequently-asked-questions

13. Tendhar T, Boulmetis J. Inner-peace and physical health: Peace of mind and physical health among Rhode Island older adults (Thesis). University of Rhode Island; 2014.

14. Paukert AL, Kraus-Schuman C, Wilson N, Snow AL, Calleo J, Kunik ME, et al. Peaceful Mind: an open trial of cognitive-behavioral therapy for anxiety in persons with dementia. Int Psychogeriatrics. 2010;22(6):1012-1021.

15. Hopwood M, Robotin MC, Porwal M, Nguyen D, Sze M. A peaceful mind: Vietnamese- Australians with liver cancer Main findings : Information about liver cancer. The University of New South Wales. 2016. Australia.

16. Centers for Diseases Control and Prevention. Worker Productivity Measures [Internet]. Centers for Diseases Control and Prevention. 2016 [cited 2020 Jul 20]. Available from: https://www.cdc.gov/workplacehealthpromotion/ model/evaluation/productivity.html
17. Mitchell RJ, Bates P. Measuring health-related productivity loss. Popul Health Manag. 2011;14(2):93-98.

18. Sabatini F. The relationship between happiness and health: Evidence from Italy. Soc Sci Med. 2014;114:178-187.

19. Pierewan AC, Tampubolon G. Happiness and Health in Europe: A Multivariate Multilevel Model. Appl Res Qual Life. 2015;10:237-252.

20. Veenhoven R. Healthy happiness: Effects of happiness on physical health and the consequences for preventive health care. J Happiness Stud. 2007;9(3):449-469.

21. Sunarno I. Konsep Sehat Menurut Perspektif Budaya Jawa (Disertasi) [The Health Concept based on the Perspectives of Javanese Culture (Dissertation)]. Universitas Airlangga Surabaya; 2012.

22. Hidajat LL. Pemaknaan Sehat-Sakit pada Masyarakat Jawa dan Bali [The Meaning of Healthy and Sick among Javanese and Balinese] [Internet]. UGM; 2005. Available from: https://ugm.ac.id/id/berita/991-pemaknaan-sehat-sakitpada-masyarakat-jawa-dan-bali

23. Hawton A, Green C, Dickens AP, Richards SH, Taylor RS, Edwards R, et al. The impact of social isolation on the health status and health-related quality of life of older people. Qual Life Res. 2011;20:56-57.

24. Grant N, Wardle J, Steptoe A. The Relationship Between Life Satisfaction and Health Behavior: A Cross-cultural Analysis of Young Adults. Int J Behav Med. 2009;16:259268.

25. Walker RJ, Smalls BL, Campbell JA, Williams JLS, Egede LE. Impact of social determinants of health on outcomes for type 2 diabetes: a systematic review. Endocrine. 2014;47:29-48.

26. Nicklett EJ, Heisler MEM, Spencer MS, Rosland AM. Direct social support and long-term health among middleaged and older adults with type 2 diabetes mellitus. Journals Gerontol - Ser B Psychol Sci Soc Sci. 2013;68(6):933-943.

27. Umberson, Debra, Karas Montez J. Social Relationships and Health: A Flashpoint for Health Policy. J Health Soc Behav. 2010;51(1_suppl):S54-66.

28. Clements, Andrea D, Ermakova AV. Surrender to God and stress: A possible link between religiosity and health. Psychol Relig Spirituality. 2012;4(2):93-107.

29. Sansone RA, Sansone LA. Gratitude and well being: the benefits of appreciation. Psychiatry. 2010;7(11):18-22.

30. Sethul Hoeur. Happiness in the Poorest Communities: Subjective Well-Being Among Adolescent Waste Pickers in Phnom Penh, Cambodia. J Psychol Res. 2018;8(4):133-144.

31. Bouckaert L, Zsolnai L. Handbook of Spirituality and Business. New York: Plagrave Macmillan; 2011. p. 269-276.

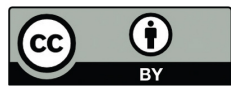

This work is licensed under a Creative Commons Attribution 